\title{
Influence of Uncertainty of Soil Hydraulic Parameters on Stability of Unsaturated Slopes Based on Bayesian Updating
}

\author{
Hsin-Fu Yeh $\mathbb{D}^{1}{ }^{1}$ Tsien-Ting Huang, ${ }^{1}$ Ya-Sin Yang, ${ }^{1}$ and Chien-Chung $\mathrm{Ke}^{2}$ \\ ${ }^{1}$ Department of Resources Engineering, National Cheng Kung University, Tainan, Taiwan \\ ${ }^{2}$ Geotechnical Engineering Research Center, Sinotech Engineering Consultants, Inc., Taipei, Taiwan \\ Correspondence should be addressed to Hsin-Fu Yeh; hfyeh22@gmail.com
}

Received 11 November 2020; Revised 13 March 2021; Accepted 18 March 2021; Published 30 March 2021

Academic Editor: Jian Luo

Copyright (C) $2021 \mathrm{Hsin}-\mathrm{Fu}$ Yeh et al. This is an open access article distributed under the Creative Commons Attribution License, which permits unrestricted use, distribution, and reproduction in any medium, provided the original work is properly cited.

\begin{abstract}
In geotechnical engineering, the soil water retention curve (SWRC) is key to solving problems arising from unsaturated soil, and the methodology used to obtain the SWRC parameters is crucial for investigating rainfall infiltration and slope stability. However, onsite measurements of soil data are expensive and time-consuming, and therefore, there is high uncertainty in the SWRC parameters due to the limited amount of data available. This study explores the impact of uncertainty in SWRC parameters on unsaturated soil slope seepage and stability under rainfall conditions. Bayesian updating was initially used to update the posterior distribution of the SWRC parameters of the model and in situ soil. Subsequently, a Markov Chain Monte Carlo (MCMC) method was used to generate random samples, and the uncertainty of the parameters was analyzed. Additionally, SWRC parametric models with different confidence intervals were created, and a hydraulic coupled model was used to evaluate the influence of the SWRC parameters (with different confidence intervals) on slope seepage and stability under rainfall conditions. The results indicated that the parameters $\alpha$ and $n$ affecting the air entry value of the soil and the pore size distribution, respectively, increased as the confidence interval percentile increased. The changes in these two parameters increased the effect of rainfall on the pressure head and volumetric water content of the soil. After rainfall infiltrated the slope, the soil volumetric water content and the internal suction stress of the soil increased, resulting in a reduction in the local factor of safety (LFS) and, hence, a decrease in the stability of the slope. These results show that the predictions for the pressure head and volumetric water content were affected by the uncertainty in the SWRC parameters, leading to errors in the slope stability analysis.
\end{abstract}

\section{Introduction}

The soil water retention curve (SWRC) is used to describe the relationship between matric suction and volumetric water content or the degree of saturation of unsaturated soil. The matric suction changes with the volumetric water content of the soil and affects the stability of the slope [1-3]. Generally, a small amount of data obtained from in situ soil cannot be used to represent the matric suction and degree of saturation for the entire SWRC. Therefore, the best fitting parameters for the SWRC were obtained using a limited amount of data. The SWRC is affected by the number of samples, the predictive model, and the estimation method used for the model parameters, leading to high uncertainty in the SWRC model parameters $[4,5]$.
Rainfall-induced landslides have caused many severe geological disasters globally [6-8]. Previous studies have found that the internal soil factors of the slope, including complex factors such as the permeability coefficient, soil strength characteristics, stress distribution, and soil deformation, are affected by rainfall infiltration [9-12]. According to the literature, the accurate estimation of soil hydraulic parameters is critical for evaluating slope stability using a hydraulic coupled model [13]. Furthermore, only a limited amount of data is available for parametric fitting and analysis owing to complex geological characteristics, limited soil samples, and measurement errors $[14,15]$. On-site measurements reflect the actual condition of the slope and can be used in the estimation of geotechnical parameters as well as the adjustment of various predictive models. The accuracy 
of the fitted parameters in the SWRC has a significant impact on geotechnical analysis [16-18].

Although the SWRC parameters reflect changes in water storage capacity and volumetric water content of the in situ soil, there is uncertainty in the fitted parameters owing to limited on-site data. Therefore, uncertainty in the model parameters is important in uncertainty analysis $[19,20]$. Bayesian updating can be used to analyze the uncertainty parameters [21,22], and its advantage lies in the generation of a posterior distribution after the likelihood function is obtained through the known distribution and on-site data. Based on a limited amount of on-site SWRC test data, Bayesian updating can be applied to quantify the uncertainty of soil hydraulic parameters $[21,23,24]$ and also be used to evaluate the spatial variability of soil properties [25]. The Markov Chain Monte Carlo (MCMC) method can effectively solve multiple integration issues in the Bayesian updating process [26]. The MCMC method is used in different research fields to analyze uncertainty, such as in flood frequency analysis, ultimate bearing capacity, and the shear strength of piles [27-29]. According to the updated posterior distribution of the model parameters, the MCMC method was executed to generate samples of the SWRC parameters. It can also be used to quantify the uncertainty of these parameters and conduct evaluation and analysis [30, 31].

The SWRC parameters are key to geotechnical modeling. The evaluation of the impact of rainfall-induced soil seepage and the stability of unsaturated slopes has an important relationship with the SWRC. Previous studies have suggested that rainfall is the main triggering factor for landslides [3234]. In recent years, relevant studies have begun including separate analyses on the SWRC model parameters and investigating the influence of soil hydraulic properties on rainfallinduced failure on the slope [31,35-37]. However, relevant study results indicate that the uncertainty of the SWRC parameters will affect the stability of unsaturated slopes; they have not quantified the stability of various points on the slope after rainfall infiltration.

The limit equilibrium method has been commonly used for analysis in traditional slope stability studies. The factor of safety (FS), an indicator of slope stability, is obtained by applying the force equilibrium principle $[38,39]$. The initial failure location and the impact of changes in pore water pressure due to rainfall infiltration on the potential instability of the slope cannot be deduced using the limit equilibrium method. The local factor of safety (LFS) is the value at each point of the slope and indicates the stability at that point; therefore, it can be used to analyze the stability of the slope at different depths and to further evaluate the potential section of failure [40].

This study analyzes the effect of SWRC parameter uncertainty on the impact of rainfall on slope stability. First, the posterior distributions of the SWRC model parameters were updated using on-site data by Bayesian updating. Then, random samples are generated from the updated posterior distributions of the parameters using the MCMC method to estimate the uncertainty. Finally, the SWRC parameters corresponding to different confidence intervals are set using random sample distributions to quantify the uncertainty in the parameters and to use the results for slope stability analysis.

\section{Conceptual Model of the Slope}

The concept of the slope model was assumed to be a homogeneous slope in this study. The shape and boundary conditions of the slope are shown in Figure 1. The slope has a height of $15 \mathrm{~m}$ and is inclined at an angle of $45^{\circ}$. The two sides of the boundaries are at a distance of $45 \mathrm{~m}$ from the crest and toe ( 3 times the height of the slope) to prevent the boundary conditions from affecting the seepage process of the slope [41]. The mesh distribution of the slope consists of four-noded quadrilateral elements $(1 \times 1 \mathrm{~m})$. According to the Central Weather Bureau regulations for extremely heavy rain, the boundary flux is given on the $A B, B C$, and $C D$ line segments of the slope surface with a rainfall intensity of $14.6 \mathrm{~mm} / \mathrm{h}$ for a duration of $96 \mathrm{~h}$. The groundwater level was applied to $30 \mathrm{~m}$ and $17 \mathrm{~m}$ from the left and right sides of the boundary, respectively. A zero flux boundary is executed along the sides of the slope above the groundwater level and along the bottom of the slope. An observation profile was set up in the middle of the slope. The observation profile and a depth of $1 \mathrm{~m}$ were affected by the inner stress and stability of the soil when rainfall infiltrates were analyzed. The values of the following parameters are utilized in the slope: saturated hydraulic conductivity at $3.24 \times 10^{-4} \mathrm{~m} / \mathrm{h}$, saturated water content of 0.51 , cohesion of $68.64 \mathrm{kPa}$, and friction angle of $21^{\circ}$.

The slope material was taken from the soil of the Babaoliao Landslide Area in Dongxing Village, Zhongpu Township, Chiayi County, Taiwan. According to the report of the Soil and Water Conservation Bureau, Council of Agriculture, Executive Yuan (2017), this area is composed of silt-bearing marlstone, which is not prone to cementation. The properties of the soil were as follows: specific gravity of 2.64 , unit weight of $18.4 \mathrm{kN} / \mathrm{m}^{3}$, porosity ratio of 0.8 , Liquid Limit (LL) of 36\%, Plastic Limit (PL) of 14\%, and uniformity coefficient of 6.6. The experimental data of the pressure cooker test of the field soil contained 64 pairs of data, and the optimal fitting of the SWRC parameters was carried out. The value of parameter $\alpha$ was 0.4818 , and the parameter $n$ was equal to 1.0919, as shown in Figure 2.

\section{Methodology}

3.1. Soil Water Retention Curve. Previous studies have proposed many numerical models to fit the SWRC parameters [42-46]. The van Genuchten (1980) model describing the relationship between soil water content or saturation and matric suction was adopted in this study. This method is the most commonly used model to fit the parameters of the SWRC, and the fitted parameters are in good agreement with the experimental results [47]. According to the van Genuchten model, the relationship between soil volumetric water content and matric suction is as follows:

$$
S=\frac{\theta-\theta_{\mathrm{r}}}{\theta_{\mathrm{s}}-\theta_{\mathrm{r}}}=\frac{1}{\left[1+(\alpha \psi)^{n}\right]^{1-n^{-1}}},
$$




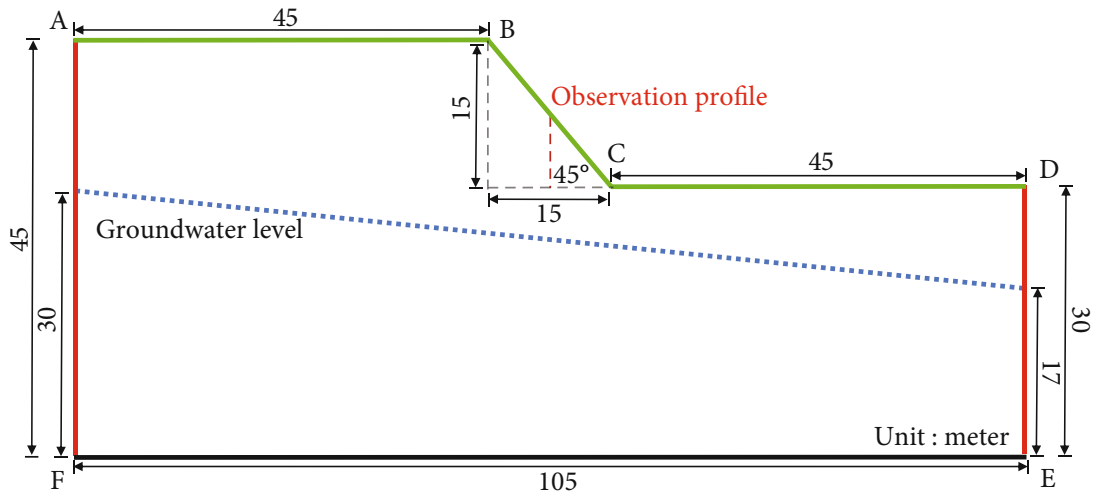

Figure 1: Conception of the slope model.

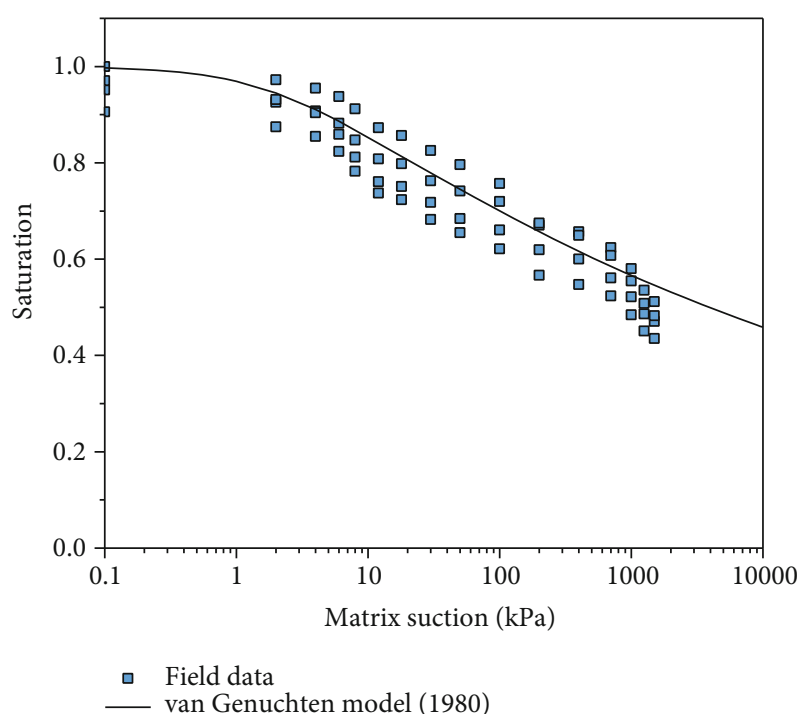

FIGURE 2: Fitting the optimal parameters of the SWRC with field data.

where $S(-)$ is the effective saturation and between 0 and 1 , $\theta\left(\mathrm{m}^{3} / \mathrm{m}^{3}\right)$ is the volumetric water content, $\theta_{\mathrm{r}}\left(\mathrm{m}^{3} / \mathrm{m}^{3}\right)$ is the residual water content, $\theta_{\mathrm{s}}\left(\mathrm{m}^{3} / \mathrm{m}^{3}\right)$ is the saturated water content, $\psi(\mathrm{kPa})$ is the matric suction, $\alpha(1 / \mathrm{m})$ is the model parameter related to soil air entry, and $n(-)$ is the model parameter related to soil pore size distribution.

3.2. Bayesian Updating. Bayesian updating is effective in evaluating model parameters and can reflect the uncertainty of its parameters through probability. This method is suitable for the analysis of geotechnical engineering, especially with limited data [48]. In this study, unknown parameters were regarded as random variables and described by probability distribution. The Bayesian updating method is used for uncertainty analysis based on the Bayesian theory [49]:

$$
p(\zeta \mid D)=\frac{p(\zeta) p(D \mid \zeta)}{p(D)}=\frac{p(\zeta) p(D \mid \zeta)}{\int_{\zeta} p(\zeta) p(D \mid \zeta) d \zeta} \propto p(\zeta) p(D \mid \zeta)
$$

where $p(\zeta)$ is the prior probability distribution of parameters, $p(D \mid \zeta)$ is the likelihood distribution and can reflect the likelihood of observation data and modal output parameters, $p(\zeta \mid D)$ is the posterior probability distribution of parameters, $p(D)$ is the normalizing constant of the probability density function, and $\zeta$ is the input parameter variable.

The prior distribution is typically based on previous literature and existing values that can represent its parameters. In geotechnical engineering, it is often assumed that its parameter is a logarithmic normal distribution because its value cannot be negative. Additionally, compared with the normal distribution, the variance of the updated posterior distribution assumed as the logarithmic normal distribution is smaller, which is closer to the true value [50]. The parameters of the prior distribution are supposed to be noncorrelated, and the logarithmic normal distribution is as follows:

$$
p(\zeta)=\prod_{i=1}^{N} \frac{1}{\sqrt{2 \pi} \zeta_{i} \sigma_{\ln \zeta_{i}}} \exp \left[-\frac{1}{2}\left(\frac{\ln \left(\zeta_{i}\right)-\mu_{\ln \zeta_{i}}}{\sigma_{\ln \zeta_{i}}}\right)^{2}\right]
$$

where $N$ is the number of random variables and $\mu_{\ln } \zeta_{i}$ and $\sigma_{\ln \zeta_{i}}$ are the logarithmic mean and standard deviation, respectively, which can be obtained from the following formulas:

$$
\begin{aligned}
& \mu_{\ln \zeta_{i}}=\ln \mu_{\zeta_{i}}-\frac{1}{2} \sigma_{\ln \zeta_{i}}^{2}, \\
& \sigma_{\ln \zeta_{i}}=\sqrt{\ln \left[1+\left(\frac{\sigma_{\zeta_{i}}}{\mu_{\zeta_{i}}}\right)^{2}\right]} .
\end{aligned}
$$

According to equation (1) of the SWRC, the uncertainty of the model parameters is estimated by the Bayesian updating method and the SWRC model parameters are treated as random variables $\zeta=[\alpha, n]$. Among them, the actual and predicted values will be slightly different, mainly due to the model error and measurement interference, which can be defined as the model output error $\varepsilon$ as follows:

$$
S_{m}=S(\zeta)+\varepsilon
$$

where $S_{m}$ is the saturation of field soil, $S(\zeta)$ is the saturation 
calculated from the van Genuchten model and is obtained for the parameter variables $\zeta=[\alpha, n], \varepsilon$ is a normal distribution, and its probability density function can be described by the following formula:

$$
p(\varepsilon)=\varphi\left(\frac{S_{m}-S(\zeta)-\mu_{\varepsilon}}{\sigma_{\varepsilon}}\right)
$$

where $\mu_{\varepsilon}$ and $\sigma_{\varepsilon}$ are the mean and standard deviation of the error $\varepsilon$, respectively, and $\varphi$ is the probability density function of the standard normal distribution. In this study, the mean and standard deviation were 0 and 0.024 , respectively.

This study assumes that the error values in the different records are statistically independent. Therefore, the likelihood function can be expressed as follows:

$$
p(D \mid \zeta)=\prod_{i=1}^{n} \frac{1}{\sqrt{2 \pi} \sigma_{\varepsilon}} \exp \left\{-\frac{1}{2}\left[\frac{S_{m}(i)-S\left(\zeta_{i}\right)}{\sigma_{\varepsilon}}\right]^{2}\right\}
$$

where $n$ is the number of measurement records, $S_{m}(i)$ is the $i$ -th measurement record of the saturation, and $S\left(\zeta_{i}\right)$ is the $i$ -th output data obtained using the van Genuchten model.

This study assumes that the model parameters $\zeta=[\alpha, n]$ satisfy the prior distribution $p(\zeta)$ in the van Genuchten model. According to the Bayesian updating method, the posterior probability density function of the model parameter $\zeta$ can be expressed as follows:

$$
p(\zeta \mid D)=c_{0} p(\zeta) \prod_{i=1}^{n} \frac{1}{\sqrt{2 \pi} \sigma_{\varepsilon}} \exp \left\{-\frac{1}{2}\left[\frac{S_{m}(i)-S\left(\zeta_{i}\right)}{\sigma_{\varepsilon}}\right]^{2}\right\},
$$

where $c_{0}$ is a constant that validates the probability density function and $p(\zeta)$ is the prior probability density function of the model parameters, which represents known knowledge.

3.3. Markov Chain Monte Carlo Method. The MCMC method is a stochastic simulation method and a powerful tool that can be utilized to generate random samples from any probability density function [51, 52]. The MCMC method is widely applied to estimate parameters and effectively solve high-dimensional integration problems [53]. It can also solve the complex integration problems of the posterior distribution in the Bayesian updating method and preserve its distribution [54]. The MCMC method has some limitations and requires an iterative evaluation of the model. Therefore, there are various types of algorithms for the MCMC method, and many scholars have proposed different algorithms [26, 55]. The DRAM algorithm [26] has superior calculation efficiency and combines the advantages of the Delayed Rejection (DR) [56] and Adaptive Metropolis (AM) algorithms [57]. The calculation efficiency is advantageous for improving the acceptance rate of the samples and accelerates the convergence speed of the process. Haario et al. (2001) proposed this method creating a covariance matrix with Gaussian distribution, calibrated by the sample path of the MCMC chain as shown in equations (9)-(11):

$$
C_{i}=\left\{\begin{array}{l}
C_{0}, \quad i \leq i_{0}, \\
s_{d} \operatorname{Cov}\left(\zeta_{0}, \cdots, \zeta_{i-1}\right)+s_{d} \varepsilon I_{d}, \quad i \geq i_{0},
\end{array}\right.
$$

where $C_{0}$ is the initial covariance at the beginning of the adaption process, $s_{d}$ depends on the parameters of the space state dimension $d, \varepsilon$ is a fixed value greater than 0 and very small, and $I_{d}$ is the unit matrix of dimension $d$. Moreover, the empirical covariance matrix is defined by the following points $\zeta_{0}, \cdots, \zeta_{k} \in R^{d}$ :

$$
\operatorname{Cov}\left(\zeta_{0}, \cdots, \zeta_{k}\right)=\frac{1}{k}\left(\sum_{i=0}^{k} \zeta_{i} \zeta_{i}^{T}-(k+1) \bar{\zeta}_{i} \zeta_{i}^{T}\right)
$$

where $\bar{\zeta}_{i}=(1 / k+1) \sum_{i=0}^{k} \zeta_{i}$, and $\zeta_{i} \in R^{d}$ is treated as the column vector. Subsequently, the covariance $C_{i}$ of $i>i_{0}$ can be obtained to satisfy the recursive equation using equation (10) to define equation (9) as follows:

$$
C_{i+1}=\frac{i-1}{i} C_{i}+\frac{s_{d}}{i}\left(i \bar{\zeta}_{i-1} \bar{\zeta}_{i}^{T}-(i+1) \bar{\zeta}_{i} \bar{\zeta}_{i}^{T}+\zeta_{i} \zeta_{i}^{T}+\varepsilon I_{d}\right)
$$

When the initial sample $\zeta_{0}$ is proposed, if the proposed sample $\zeta_{i}^{(1)}$ is accepted, the acceptance probability is calculated as follows:

$$
\alpha_{1}\left(\zeta_{i-1}, \zeta_{i}^{(1)}\right)=1 \wedge \frac{p\left(\zeta_{i}^{(1)} \mid D\right) q_{1}\left(\zeta_{i}^{(1)}, \zeta_{i-1}\right)}{p\left(\zeta_{i-1} \mid D\right) q_{1}\left(\zeta_{i-1}, \zeta_{i}^{(1)}\right)}
$$

where $p\left(\zeta_{i}^{(1)} \mid D\right)$ is the target distribution, and $q_{1}$ is the first proposed distribution. If $\zeta_{i}^{(1)}$ is rejected, the probability of acceptance of the distribution proposed in the second stage is as follows:

$\alpha_{2}\left(\zeta_{i-1}, \zeta_{i}^{(2)}\right)=1 \wedge \frac{p\left(\zeta_{i}^{(2)} \mid D\right) q_{1}\left(\zeta_{i}^{(2)}, \zeta_{i}^{(1)}\right) q_{2}\left(\zeta_{i}^{(2)}, \zeta_{i}^{(1)}, \zeta_{i-1}\right)\left[1-\alpha_{1}\left(\zeta_{i}^{(2)}, \zeta_{i}^{(1)}\right)\right]}{p\left(\zeta_{i-1} \mid D\right) q_{1}\left(\zeta_{i-1}, \zeta_{i}^{(1)}\right) q_{2}\left(\zeta_{i-1}, \zeta_{i}^{(1)}, \zeta_{i}^{(2)}\right)\left[1-\alpha_{1}\left(\zeta_{i-1}, \zeta_{i}^{(1)}\right)\right]}$,

where $q_{2}$ is the second proposed distribution. The previous steps are repeated until the target number of samples is completed [58].

3.4. The Process of Uncertainty Estimation. In this study, the Bayesian updating method and the MCMC method were applied, and different confidence intervals of the parameters were constructed to explore and quantify the uncertainty of the SWRC parameters. The Bayesian updating method was used to generate the posterior distribution of the SWRC parameters, and then the MCMC method was used to generate a random sample of the SWRC parameters for the 
posterior distribution. The related evaluation steps for the uncertainty of the parameters are as follows.

(i) The prior distribution of the model parameters is assumed to be a logarithmic normal distribution in this study

(ii) The likelihood function of the Bayesian updating method is defined by the error between the saturation and matric suction data obtained from the field measurement and the fitting parameter output by the selected model

(iii) The posterior probability density function obtained by the Bayesian updating method is regarded as the target distribution function. Then, the MCMC method combined with the DRAM algorithm was used to generate random samples from its probability density function

(iv) The random samples generated from the calculations were used to represent the posterior distribution. In this study, 40,000 samples were obtained

(v) The parameters of different confidence intervals for random samples of the posterior distribution were established, and different percentiles were obtained to quantify the influence of the parameter uncertainty

3.5. Seepage Analysis. The seepage process in unsaturated soil was evaluated and analyzed using the HYDRUS model software [59]. This software is widely used to analyze unsaturated soils and can calculate different soil layers and soil hydraulic characteristics. The governing equation (Richards equation) of the transient and two-dimensional seepage analysis of unsaturated soil ( $x$ is the horizontal direction, and $z$ is the vertical direction) is rewritten using equation (1), as shown below:

$$
\frac{\partial \theta(h)}{\partial t}=\nabla \cdot K(h) \nabla H+W
$$

where $H$ is the total pressure head, $t$ is time, $h$ is the pressure head or suction head, $W$ is the flow, $\theta(h)$ is the volumetric water content under different pressure heads, and $K(h)$ is the unsaturated hydraulic conductivity function.

Equation (14) is adopted to estimate the hydraulic conductivity, which can be used for saturated and unsaturated soils, as shown below:

$$
K(h)=K_{\mathrm{s}} S^{1 / 2}\left[1-\left(1-S^{1 / m}\right)^{m}\right]^{2}
$$

where $m=1-n^{-1}$ and $K_{\mathrm{s}}$ is the saturated hydraulic conductivity and is often regarded as a fixed value.

The water storage capacity in unsaturated soil depends on the matric suction and can be characterized by SWRC. The hydraulic properties are affected by the uncertainty of the parameters $\alpha$ and $n$. In unsaturated soil slopes, the infiltration of initial rainfall depends on rainfall intensity, duration, groundwater condition, saturated permeability coefficient, hydraulic conductivity function, and SWRC [60-62]. This study is aimed at exploring the influence of uncertainty in SWRC parameters on rainfall-induced slope stability. According to the conceptual model of the slope, the SWRC parameters with different confidence intervals were used for seepage analysis.

3.6. Slope Stability Analysis. The LFS proposed by Lu et al. [40] was adopted to analyze the slope stability in this study. This method calculates the current stress state and the stability of each point in the slope. Additionally, it is different from the limit equilibrium method, which provides a value for each slope slice as a safety factor in previous studies. $\mathrm{Lu}$ et al. [40] compared the results of the LFS method with other factors of safety methods to prove that the initiation and the geometry of the potential failure surface LFS are based on the Mohr-Coulomb failure criterion, according to which the LFS is defined as shown below:

$$
\mathrm{LFS}=\frac{\tau^{*}}{\tau}=\frac{\cos \varphi^{\prime}}{\sigma_{1}-\sigma_{3}}\left[2 c^{\prime}+\left(\sigma_{1}+\sigma_{3}-2 \sigma_{\mathrm{s}}\right) \tan \varphi^{\prime}\right]
$$

where $\tau^{*}$ is the current stress state, $\tau$ is the stress state when failure occurs, $\varphi^{\prime}$ is the effective friction angle, $\sigma_{1}$ is the maximum principal stress, $\sigma_{3}$ is the minimum principal stress, $c^{\prime}$ is the effective cohesion, and $\sigma_{\mathrm{s}}$ is the suction stress, as shown in Figure 3. If the LFS is larger, the slope stability is higher. Otherwise, the stability is reduced.

This study is based on the results of the seepage analysis for slope stability analysis. The LFS of each point inside the slope was further calculated using the percentiles of different confidence intervals and parameter properties. Finally, the impact of the uncertainty of the SWRC parameters on the slope stability was quantified and evaluated.

\section{Results and Discussion}

4.1. Results of Bayesian Updating and Uncertainty. In this study, an uncertainty analysis was performed using volumetric water content and matric suction data from the soil in the Babaoliao Landslide Area in Chiayi, Taiwan, and the SWRC model. The MCMC method was used, and the Markov chain iteration conditions were established using the posterior distribution obtained from Bayesian updating. Thereafter, the posterior distribution converged, and random samples were generated for uncertainty analysis. The prior distributions of random variables $\alpha$ and $n$ were assumed to have independent lognormal distributions, with the prior mean and standard deviation of $\alpha$ being 0.58 and 1.096, respectively, and those of $n$ being 1.0989 and 0.0199, respectively. Subsequently, the MCMC method and the posterior probability density function from Bayesian updating were used to generate 40,000 random model parameter samples for the SWRC parameters. The iterative process for random sampling is shown in Figure 4.

In this study, 40,000 sets of postconvergence random parameter samples were considered the posterior distribution, with the posterior mean and standard deviation of $\alpha$ 


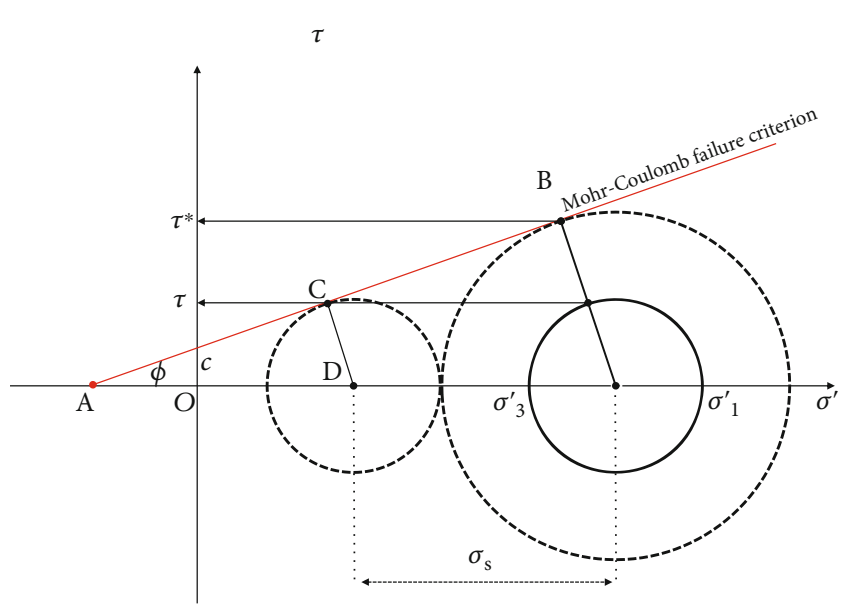

Figure 3: Conception of the local factor of safety.

being 0.6342 and 0.1565 , respectively, and those of $n$ being 1.0979 and 0.0058 , respectively.

From the 40,000 sets of generated model parameters $\alpha$ and $n$ mentioned above, and given specific matric suction values, 40,000 sets of the degree of saturation values were obtained. The SWRC with different confidence intervals was established using the obtained degree of saturation and matric suction values, and the effect of the SWRC parameters with different confidence intervals on seepage and the slope was investigated. The SWRC parameters were classified according to $50 \%$ and $95 \%$ confidence intervals, which were then classified into upper and lower limits along the mean curve and expressed in percentiles (PCTs), respectively. The corresponding PCTs of the upper and lower limits of the confidence intervals were $25 \% / 75 \%$ and $2.5 \% / 97.5 \%$, respectively, and the mean curve corresponded to the PCT $=50 \%$. The SWRC parameters changed with the PCTs, as shown in Table 1; the higher the PCT, the lower the model parameters $\alpha$ and $n$. This created a higher soil water storage capacity and a gentler slope for the curve, as shown in Figure 5. The ranges of the SWRC model parameters $\alpha$ and $n$ corresponding to the $95 \%$ confidence interval were $(1.0175,0.395)$ and (1.1101, 1.0868), respectively. The model parameters obtained were subsequently used for slope seepage and stability analyses, and the results are presented in the following two subsections. Using the method in this study, the confidence intervals of the SWRC could be effectively obtained, the model parameters could be estimated, and the uncertainty of the SWRC parameters could be quantified. Additionally, the accuracy of the uncertainty estimations and SWRC parameters was improved using on-site measurement data.

4.2. Effect of Uncertainty on Seepage Analysis. This section discusses the effects on the pressure head due to the uncertainty of the parameters in the SWRC derived from unsaturated soil. The SWRC parameters of different PCTs were used for transient seepage analysis, and a graph was plotted to show the changes in the pressure head within the slope. At the initial state $(t=0 \mathrm{~h})$, the pressure head in the slope changed linearly with depth. Thereafter, rainfall conditions were added, with rainfall durations of $12,24,48,72$, and
$96 \mathrm{~h}$. The change in pressure heads within the observation profile in the slope with the parameters of different PCTs was observed, as shown in Figure 6. This study imposed an hourly rainfall of $14.6 \mathrm{~mm}$ on the slope. Figures $6(\mathrm{a})-6(\mathrm{e})$ show the pressure head changes in the observation profiles for the SWRC with parameters of different PCTs, namely, $2.5 \%, 25 \%, 50 \%, 75 \%$, and $97.5 \%$; their model parameters, $\alpha$ and $n$, are shown in Table 1 . In the numerical simulation analysis, as the rainfall infiltrated the slope surface under continuous rainfall conditions, the wetting front moved downward, resulting in a decrease in the pressure head. This movement of the pressure head from a negative value to a positive value is described as a decrease in the pressure head in this study.

The model parameters of different PCTs obtained through statistical analysis would affect the change in the pressure head in the soil with depth. For soils belonging to the PCT $=2.5 \%$, the wetting front was clear, as shown in Figure 6(a). When water continued to flow down through the soil, the pressure head in the shallow slopes decreased, and the wetting front of the soil slowly moved downward. After $96 \mathrm{~h}$ of rain, the depth of the wetting front decreased by approximately $2 \mathrm{~m}$. Thus, the reduction in the pressure head primarily occurred in the shallow areas, which could be attributed to the relatively poor permeability of the soil. The pressure head at depth was not affected, nor was it affected by rainfall duration on the downward movement of the wetting front, which moved downward at a relatively slow speed. As shown in Figure 6(b), for the soil at PCT = $25 \%$, the pressure head curve was similar to that of the PCT $=2.5 \%$, and the pressure head near the ground surface decreased with time at a considerably rapid rate of decline. Additionally, it was evident that the pressure head at depth remained constant, while the transition zone between the infiltration zone and the still-unaffected zone remained obvious. For the PCTs as a whole, the wetting front moved downward at approximately the same speed and depth in the first $24 \mathrm{~h}$ of rainfall; however, after the first $48 \mathrm{~h}$ of rainfall, the pressure head of the slopes with PCTs above $25 \%$ was affected.

At higher PCTs, the wetting front moved downward at a relatively faster rate after $48 \mathrm{~h}$ of rainfall; after it reached a depth of approximately $3 \mathrm{~m}$, the deeper soil was no longer affected, as shown in Figure 6. The effect of rainfall on the rate of downward movement of the wetting front increased gradually with an increase in PCT. During the process, the rate of movement of the wetting front was different, indicating that the behavior of the rainfall was related to the SWRC and hydraulic conductivity. The pressure head profiles in the results indicate that the most significant differences among the different PCTs should be visible in the shallow regions. In this study, the slope soil hydraulic conductivity of different PCTs was calculated using equation (15), as shown in Figure 7. Although the saturated hydraulic conductivity was the same for each PCT, there were differences in the hydraulic conductivities among the different PCTs in the unsaturated phase. Unsaturated soils with higher PCTs had higher hydraulic conductivities; conversely, unsaturated soils of lower PCTs had lower conductivities. Therefore, for the same rainfall intensity and duration and the same saturated hydraulic conductivity, soils with higher PCTs had higher 


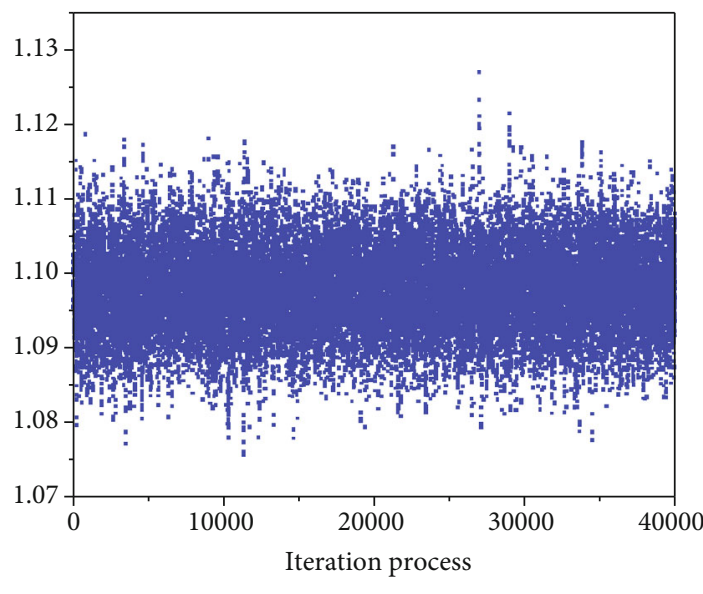

(a) Parameter $\alpha$

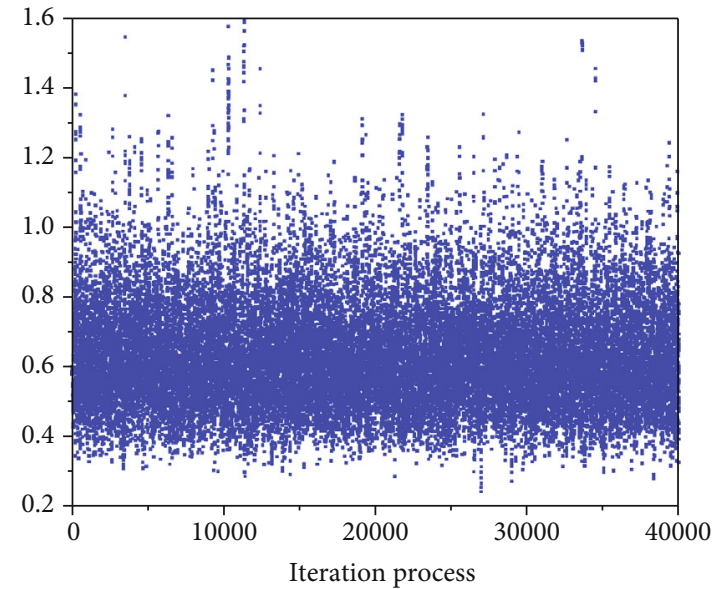

(b) Parameter $n$

Figure 4: Iteration process of random samples of parameters $\alpha$ and $n$.

TABLE 1: Different percentiles of parameters of the SWRC.

\begin{tabular}{lccccc}
\hline $\begin{array}{l}\text { Confidence } \\
\text { level }\end{array}$ & $\begin{array}{c}\text { Lower } \\
\text { bound of } \\
95 \%\end{array}$ & $\begin{array}{c}\text { Lower } \\
\text { bound of } \\
50 \%\end{array}$ & $\begin{array}{c}\text { Mean } \\
\text { curve }\end{array}$ & $\begin{array}{c}\text { Upper } \\
\text { bound of } \\
50 \%\end{array}$ & $\begin{array}{c}\text { Upper } \\
\text { bound of } \\
95 \%\end{array}$ \\
\hline Percentiles & $2.5 \%$ & $25 \%$ & $50 \%$ & $75 \%$ & $97.5 \%$ \\
$\alpha(1 / \mathrm{m})$ & 1.0175 & 0.7368 & 0.6099 & 0.5235 & 0.395 \\
$n$ & 1.1101 & 1.1016 & 1.0978 & 1.0940 & 1.0868 \\
\hline
\end{tabular}

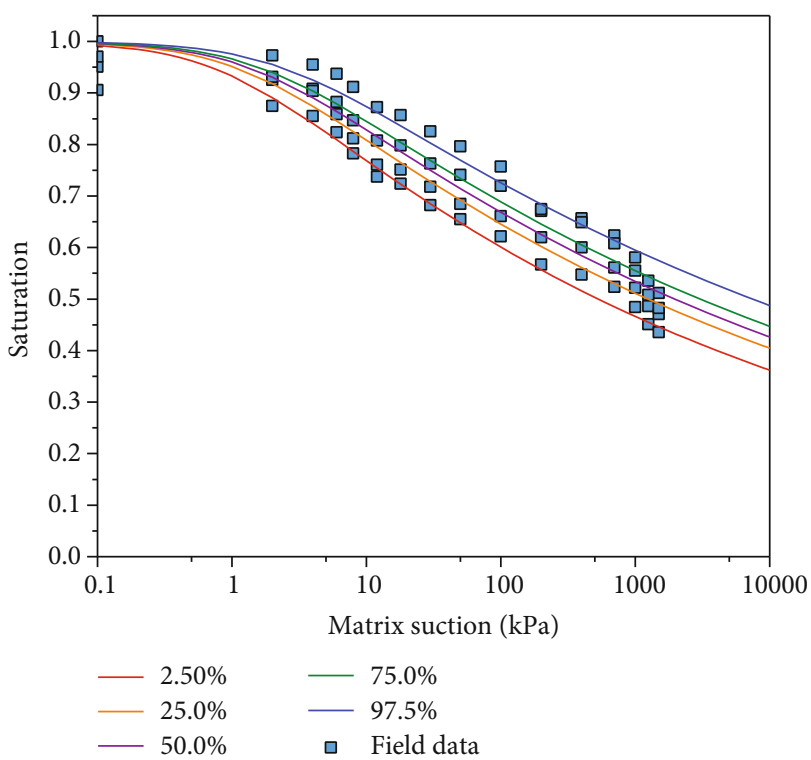

FIGURE 5: Different percentiles of parameters of the SWRC model.

conductivity and greater water storage capacity in the unsaturated state. Accordingly, in soils with higher PCTs, the wetting front moved down more quickly, and the dissipation of the pressure head was faster as well. Thus, it is evident that the uncertainty in the SWRC parameters will lead to errors in the predicted pressure head profile.
4.3. Effect of Rainfall Duration on the Pressure Head. Given the same rainfall duration $(96 \mathrm{~h})$, the rate of movement of the wetting front was affected by the SWRC parameter PCTs. The pressure head curve of the slope observation profile is shown in Figure 8. As the PCT increased, the soil water storage capacity increased, the downward movement speed of the wetting front increased, and the pressure head disappeared more easily. Pressure heads at the same depth were greater for smaller PCTs. These results show that the seepage behavior of the entire slope controls the stability of the slope.

Next, this study investigated the changes in and the effect on the pressure head at a single depth at different PCTs with changes in the rainfall duration, as shown in Figure 9. The curve in Figure 9 shows that the pressure head decreases with increasing rainfall duration at a depth of $1 \mathrm{~m}$ in the slope observation profile. The pressure head curve indicated that at the $\mathrm{PCT}=2.5 \%$, the pressure head dropped from $-12.51 \mathrm{~m}$ to $-2.81 \mathrm{~m}$ over time, with a rate of change of $77.5 \%$; at the PCT $=97.5 \%$, the pressure head dropped with time from $-12.51 \mathrm{~m}$ to $-1.42 \mathrm{~m}$, with a rate of change of $88.6 \%$. These results show that the lower the PCT, the smaller is the change in the pressure head.

The magnitudes of the drop in the pressure head for the different PCTs are clearly observed in Figure 9. These magnitudes depended on the PCT of the SWRC parameters; as the PCT increased, the magnitude of the drop in the pressure head increased. Higher PCT values led to higher hydraulic conductivities and faster water flow in the unsaturated state, leading to greater pressure head drops. Therefore, the different SWRC parameter PCTs substantially impacted the slope seepage analysis under different rainfall conditions.

4.4. Effect of Uncertainty on Slope Stability. In the stability analysis, the pressure head and soil volumetric water content distribution data obtained from the seepage analysis were used to calculate the slope stability. In this study, LFS was used to calculate the instantaneous stress at each point at different depths. The results indicate that slope stability is mainly affected by the rainfall infiltration process. Rainfall 


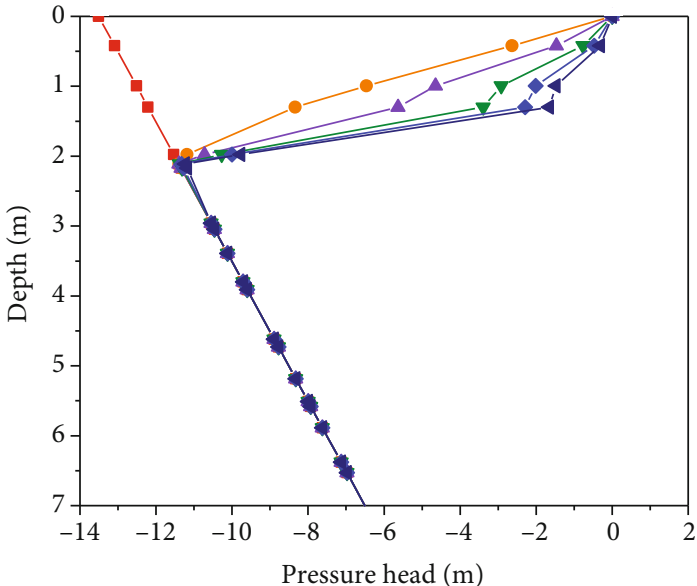

(a) Percentile $=2.5 \%$

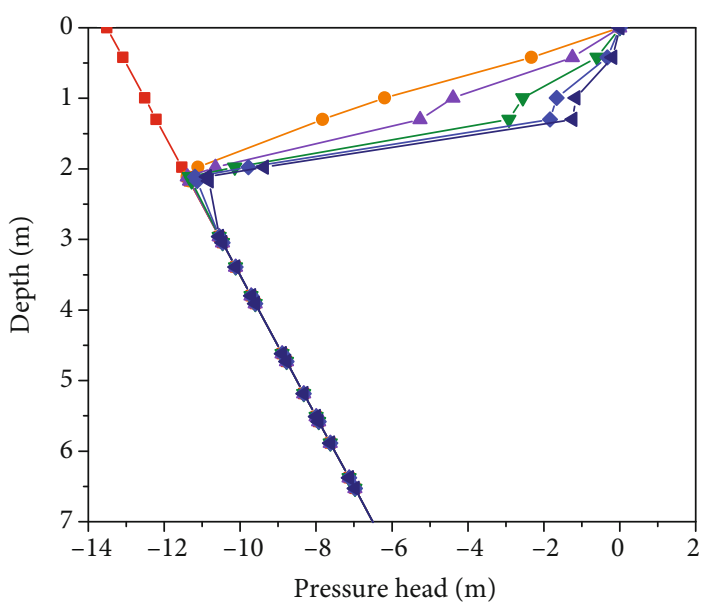

(c) Percentile $=50 \%$

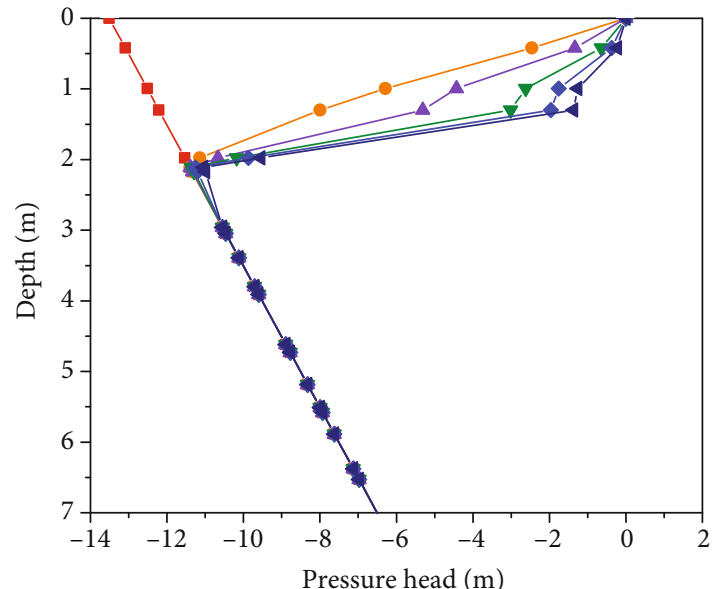

(b) Percentile $=25 \%$

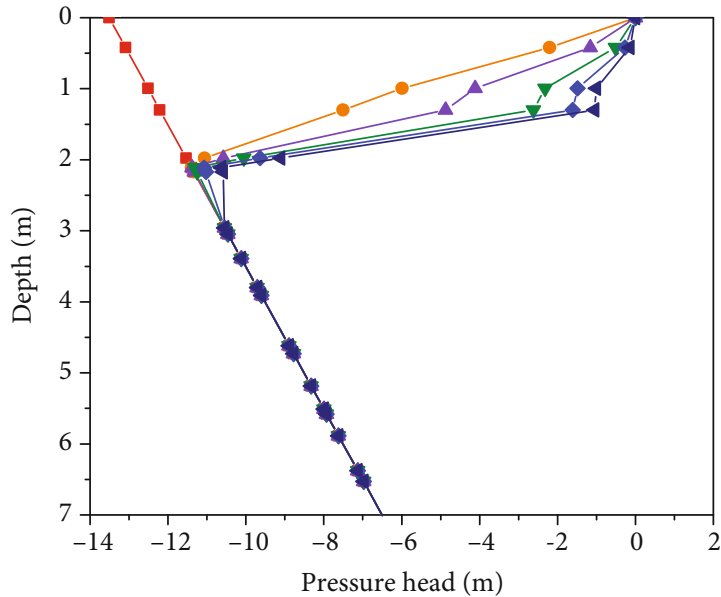

(d) Percentile $=75 \%$

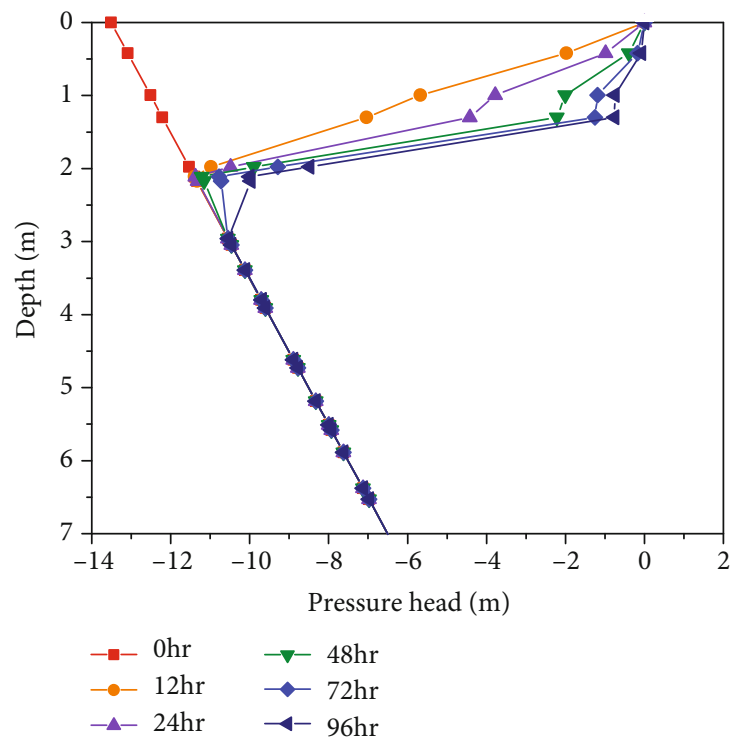

(e) Percentile $=97.5 \%$

FIGURE 6: Pressure head at the observation profile with different percentiles of the SWRC during different rainfall durations. 


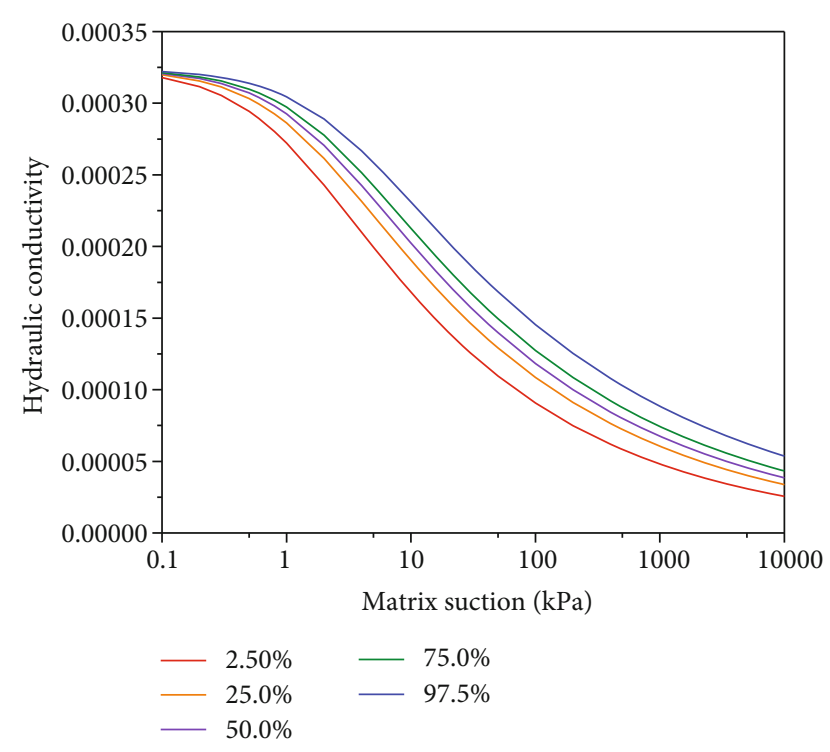

FIGURE 7: Soil hydraulic conductivity with different percentiles of the SWRC.

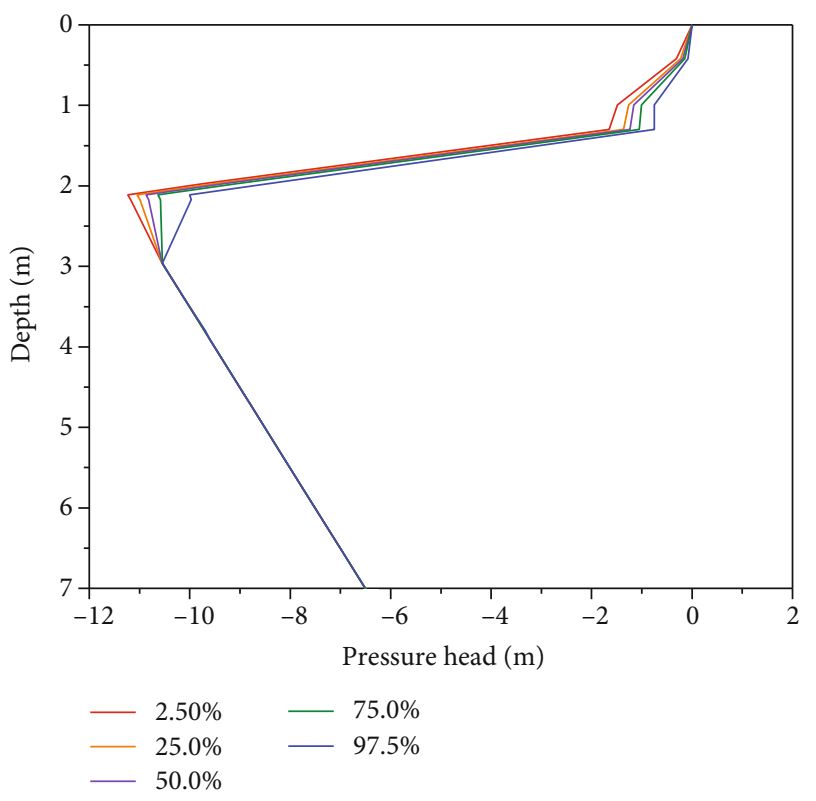

Figure 8: Pressure head at the observation profile with different percentiles of the SWRC $(t=96 \mathrm{~h})$.

infiltration caused the pressure head to decrease and the soil volumetric water content to increase, thereby affecting internal stress changes in the soil and leading to a decrease in slope stability. Therefore, this section primarily analyzes the soil volumetric water content, suction stress, and LFS. The soil volumetric water content for the different PCTs changed according to rainfall duration. As seen in Figure 10, the volumetric water content for PCT $=2.5 \%$ increased from 0.402 to 0.464 , while the volumetric water content for PCT $=97.5 \%$ increased from 0.436 to 0.494 . The final volumetric water content for PCT $=2.5 \%$ was lower than that for PCT $=97.5 \%$.

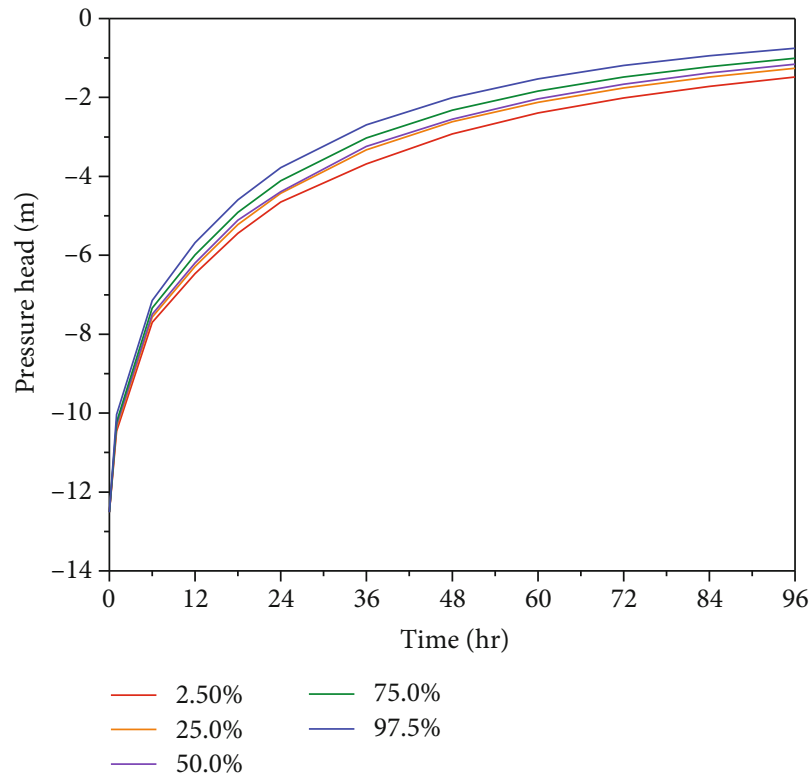

FIgURe 9: Pressure head at $1 \mathrm{~m}$ depth of the observation profile with different percentiles of the SWRC.

Furthermore, the results showed that the initial volumetric water content was lower when the PCT was low and vice versa. This is related to the water storage capacity being higher when the PCT level was higher. The internal stress of the soil also changed owing to the rainfall infiltration. The variation in the soil suction stress with rainfall duration for the different PCTs is shown in Figure 11. The results show that the suction stress for the PCT $=2.5 \%$ decreased from -92.25 to -12.82 , with a rate of decrease of $86.1 \%$, while the suction stress for the PCT $=97.5 \%$ decreased from -105.49 to -7.14 , with a rate of decrease of $93.2 \%$. The decrease in soil suction stress at lower PCTs after rainfall infiltration was relatively low. As soils at the higher PCTs had greater water storage capacities, more rainwater could be stored, thus leading to an increase in the soil volumetric water content within the slope, resulting in a decrease in the soil suction stress.

Finally, the LFSs of the slopes were analyzed in this study. Figure 12 shows the variation of the LFS with depth for different PCTs after $96 \mathrm{~h}$ of rainfall. The results showed that the soil at shallow depths failed for every PCT $(\mathrm{LFS}<1)$. The failure depths at the PCT $=2.5 \%$ and $97.5 \%$ were approximately $0.4 \mathrm{~m}$ and $0.7 \mathrm{~m}$, respectively. The LFSs for the different PCTs were mostly similar at the initial state. However, after rainfall infiltration, the decrease in the LFS for the soils at lower PCTs was lower, while that for the soils at higher PCTs was higher, as shown in Figure 13. The results show that the LFSs were mostly similar for a rainfall duration of $6 \mathrm{~h}$, with no particular differences. However, at $12 \mathrm{~h}$ onwards, the variation in the LFSs at different PCTs began to differ. Between $12 \mathrm{~h}$ and $96 \mathrm{~h}$ of rainfall, the LFS at the $\mathrm{PCT}=2.5 \%$ decreased from 1.83 to 1.38 , with a rate of decrease of $24.5 \%$, while that at the PCT $=97.5 \%$ decreased from 1.68 to 1.20 , with a rate of decrease of $28.5 \%$. These results show that the SWRC parameter uncertainty has a 


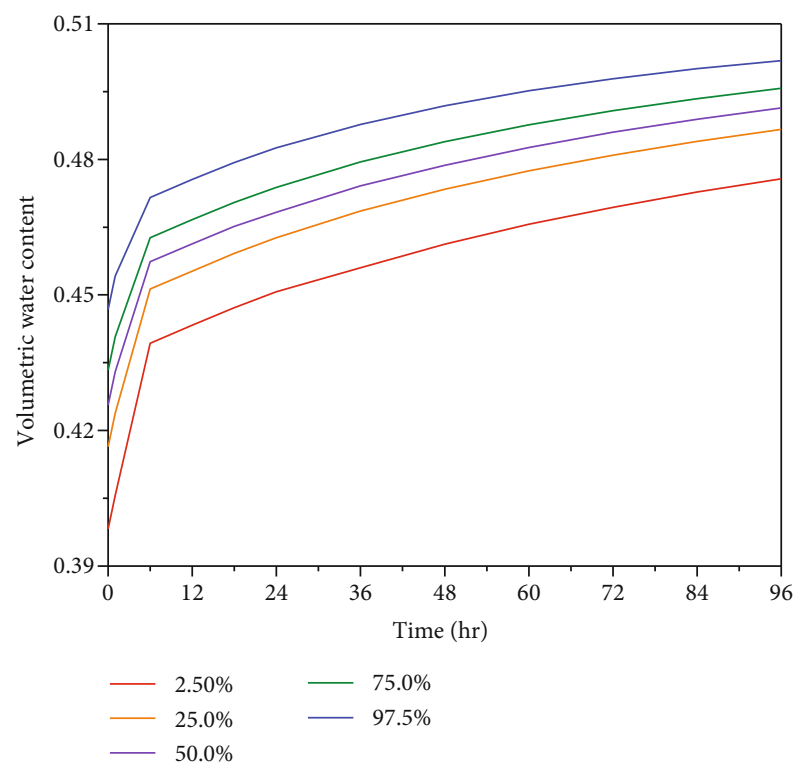

Figure 10: Volumetric water content at $1 \mathrm{~m}$ depth of the observation profile with different percentiles of the SWRC.

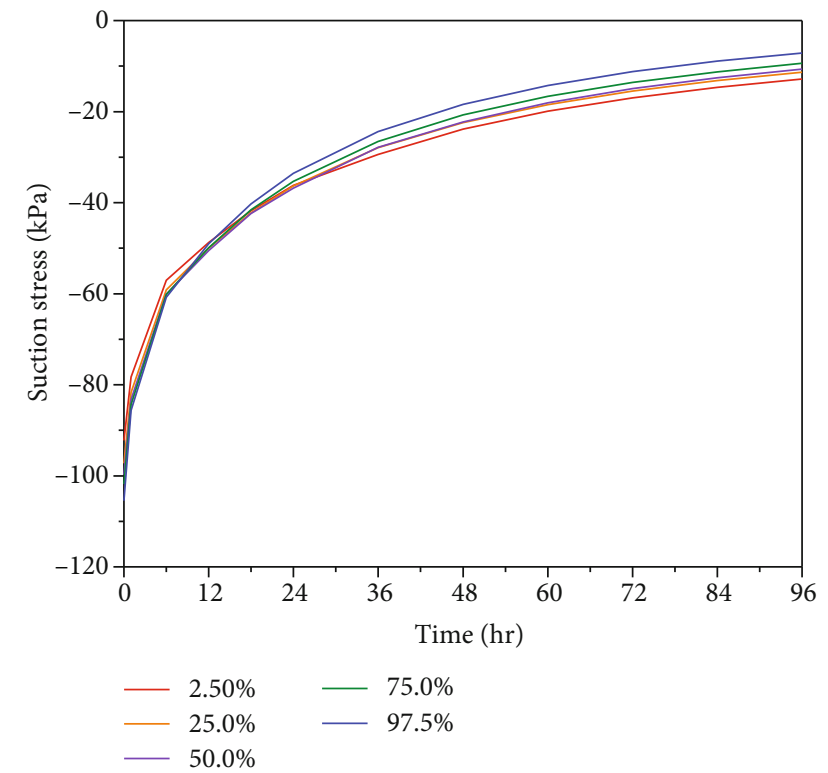

FIGURE 11: Soil suction stress at $1 \mathrm{~m}$ depth of the observation profile with different percentiles of the SWRC.

considerable effect on the stability of unsaturated soil slopes. Figures 10-13 show that the slope stability results were related to the volumetric water content and stress distribution within the soil.

For the soil adopted in this study, the rainfall only affected the pressure head at shallow depths of the slope, while its effect at deeper depths could be ignored. Therefore, the LFS of the slope was higher. When the PCT increased from $2.5 \%$ to $25 \%$, the decrease in the LFS increased from 1.28 to 1.35 . As the PCTs increased, the decrease in the LFS increased, reaching a maximum drop of 1.50 . This corresponds to a rate of decrease of $53.8 \%$. After $96 \mathrm{~h}$ of rainfall,

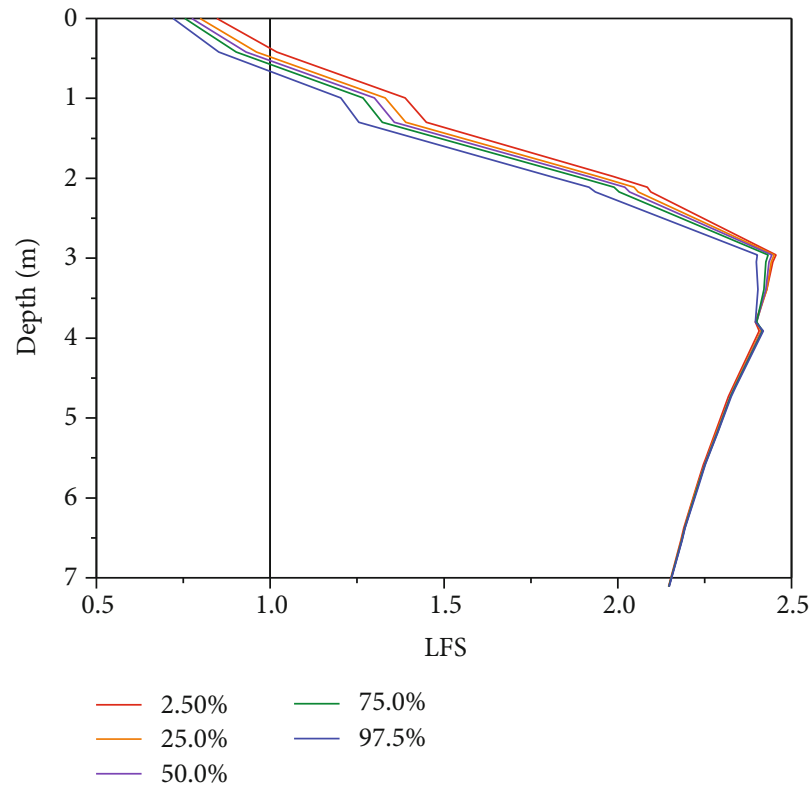

FIGURE 12: Local factor of safety at the observation profile with different percentiles of the SWRC $(t=96 \mathrm{~h})$.

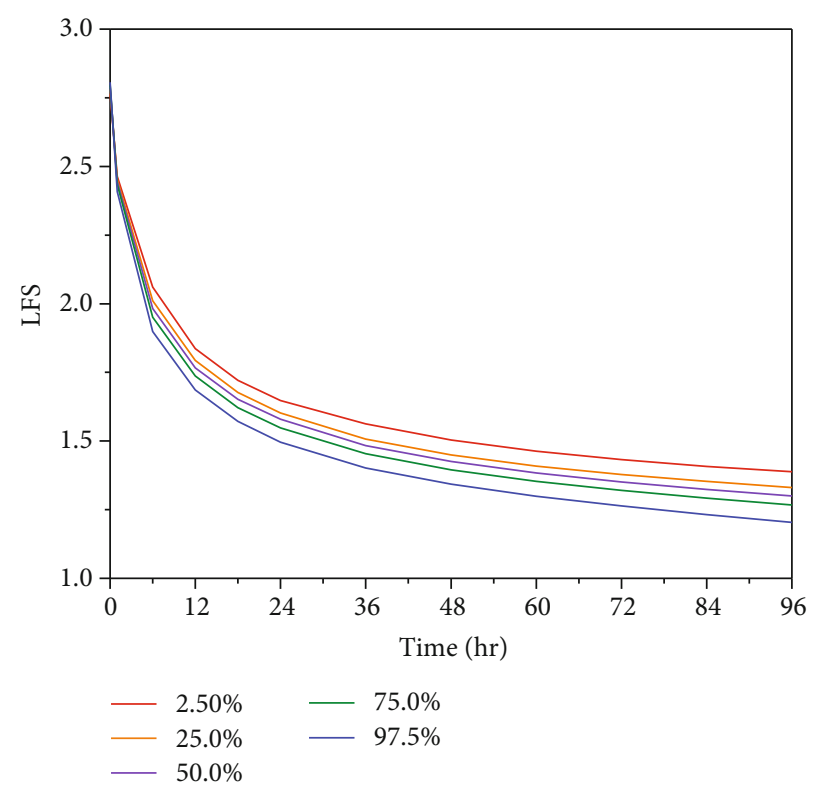

FIgURE 13: Local factor of safety at the observation profile with different percentiles of the SWRC.

the soil volumetric water content increased, and the wetting front migrated to the shallow soil layer, leading to a decrease in suction stress and LFS.

As expected, the LFS was lowest for the soil corresponding to the highest PCT. This was because the unsaturated soil had the highest permeability, and a higher PCT indicated a higher water storage capacity and volumetric water content, causing the water to move more quickly along the slope. The magnitude of the increase in the LFS increased with PCT. Therefore, the uncertainty of the SWRC model parameters affects the slope stability. 


\section{Conclusion}

In this study, the Bayesian updating method and the MCMC method were applied to evaluate the uncertainty of the SWRC model parameters and quantify the effect of parameter uncertainty on the seepage and stability of unsaturated soil slopes under rainfall conditions. The conclusions of this study can be summarized as follows.

(1) The uncertainty in the SWRC model parameters was effectively estimated using the Bayesian updating method. By combining the MCMC method and the DRAM algorithm, the posterior distribution of the SWRC model parameters can be effectively generated to perform seepage and stability analyses by setting specific confidence intervals

(2) The effect of uncertainty on the seepage and stability of unsaturated soil slopes under rainfall conditions was investigated using the SWRC model parameters at different confidence intervals. The results show that the hydraulic conductivity and pressure head distribution in the unsaturated soil were related to the confidence interval under the same rainfall conditions. Moreover, under the same rainfall conditions, the higher the PCT, the higher the hydraulic conductivity and the greater the drop in the pressure head. This implies a higher water storage capacity of the soil and faster movement of the wetting front. Therefore, the LFS of slopes corresponding to higher percentile SWRC parameters was relatively low and displayed more significant declines, thereby affecting the slope stability

(3) From the results of this study, we found that the uncertainty in the SWRC parameters was extremely important for the stability analysis of slopes affected by rainfall. As parameter uncertainty may also affect the design and planning of future geotechnical projects, it should be considered in engineering project evaluations in the future

\section{Data Availability}

The data that support the findings of this study are available from the corresponding author on request.

\section{Conflicts of Interest}

The authors declare that they have no conflicts of interest.

\section{References}

[1] D. G. Fredlund and A. Xing, "Equations for the soil-water characteristic curve," Canadian Geotechnical Journal, vol. 31, no. 4, pp. 521-532, 1994.

[2] J. Sedano and S. Vanapalli, "Experimental investigation of the relationship between the critical state shear strength of unsaturated soils and the soil-water characteristic curve," International Journal of Geotechnical Engineering, vol. 5, no. 1, pp. 1-8, 2011.
[3] X. Li, J. Li, and L. Zhang, "Predicting bimodal soil-water characteristic curves and permeability functions using physically based parameters," Computers and Geotechnics, vol. 57, pp. 85-96, 2014.

[4] M. Wijaya and E. Leong, "Equation for unimodal and bimodal soil-water characteristic curves," Soils and Foundations, vol. 56, no. 2, pp. 291-300, 2016.

[5] M. Calamak, A. Melih Yanmaz, and E. Kentel, "Probabilistic evaluation of the effects of uncertainty in transient seepage parameters," Journal of Geotechnical and Geoenvironmental Engineering, vol. 143, no. 9, article 06017009, 2017.

[6] D. G. Fredlund, "Unsaturated soil mechanics in engineering practice," Journal of Geotechnical and Geoenvironmental Engineering, vol. 132, no. 3, pp. 286-321, 2006.

[7] D. Tang, D.-Q. Li, and Z.-J. Cao, "Slope stability analysis in the Three Gorges Reservoir Area considering effect of antecedent rainfall," Georisk: Assessment and Management of Risk for Engineered Systems and Geohazards, vol. 11, no. 2, pp. 161$172,2016$.

[8] L. Zhang, J. Li, X. Li, J. Zhang, and H. Zhu, Rainfall-Induced Soil Slope Failure: Stability Analysis and Probabilistic Assessment, CRC Press, 2018.

[9] G. Ye, F. Zhang, A. Yashima, T. Sumi, and T. Ikemura, "Numerical analyses on progressive failure of slope due to heavy rain with 2D and 3D FEM," Soils and Foundations, vol. 45, no. 2, pp. 1-15, 2005.

[10] Y. Zhou, C. Cheuk, and L. Tham, "Deformation and crack development of a nailed loose fill slope subjected to water infiltration," Landslides, vol. 6, no. 4, pp. 299-308, 2009.

[11] A. N. Zhou, D. Sheng, and J. P. Carter, "Modelling the effect of initial density on soil-water characteristic curves," Géotechnique, vol. 62, no. 8, pp. 669-680, 2012.

[12] Z. Han and S. Vanapalli, "Stiffness and shear strength of unsaturated soils in relation to soil-water characteristic curve," Géotechnique, vol. 66, no. 8, pp. 627-647, 2016.

[13] K.-K. Phoon and F. H. Kulhawy, "Characterization of geotechnical variability," Canadian Geotechnical Journal, vol. 36, no. 4, pp. 612-624, 1999.

[14] S.-H. Jiang, D.-Q. Li, L.-M. Zhang, and C.-B. Zhou, "Slope reliability analysis considering spatially variable shear strength parameters using a non-intrusive stochastic finite element method," Engineering Geology, vol. 168, pp. 120-128, 2014.

[15] D.-Q. Li, T. Xiao, Z.-J. Cao, C.-B. Zhou, and L.-M. Zhang, "Enhancement of random finite element method in reliability analysis and risk assessment of soil slopes using subset simulation," Landslides, vol. 13, no. 2, pp. 293-303, 2016.

[16] P. Vardon, K. Liu, and M. Hicks, "Reduction of slope stability uncertainty based on hydraulic measurement via inverse analysis," Georisk: Assessment and Management of Risk for Engineered Systems and Geohazards, vol. 10, no. 3, pp. 223-240, 2016.

[17] X. Luo, W. Liu, M. Fu, and J. Huang, "Probabilistic analysis of soil-water characteristic curve with Bayesian approach and its application on slope stability under rainfall via a difference equations approach," Journal of Difference Equations and Applications, vol. 23, no. 1-2, pp. 322-333, 2017.

[18] J. Zhang, H. Wang, H. Huang, and L. Chen, "System reliability analysis of soil slopes stabilized with piles," Engineering Geology, vol. 229, pp. 45-52, 2017.

[19] L. Zhang, J. Zhang, L. Zhang, and W. Tang, "Back analysis of slope failure with Markov chain Monte Carlo simulation," 
Computers and Geotechnics, vol. 37, no. 7-8, pp. 905-912, 2010.

[20] M. Bouda, A. N. Rousseau, B. Konan, P. Gagnon, and S. J. Gumiere, "Bayesian uncertainty analysis of the distributed hydrological model HYDROTEL," Journal of Hydrologic Engineering, vol. 17, no. 9, pp. 1021-1032, 2011.

[21] L. Wang, Z.-J. Cao, D.-Q. Li, K.-K. Phoon, and S.-K. Au, "Determination of site-specific soil-water characteristic curve from a limited number of test data - a Bayesian perspective," Geoscience Frontiers, vol. 9, no. 6, pp. 1665-1677, 2018.

[22] W. Liu, X. Luo, F. Huang, and M. Fu, "Prediction of soil water retention curve using Bayesian updating from limited measurement data," Applied Mathematical Modelling, vol. 76, pp. 380-395, 2019.

[23] S.-H. Jiang, I. Papaioannou, and D. Straub, "Bayesian updating of slope reliability in spatially variable soils with in- situ measurements," Engineering Geology, vol. 239, pp. 310-320, 2018.

[24] D.-Q. Li, L. Wang, Z.-J. Cao, and X.-H. Qi, "Reliability analysis of unsaturated slope stability considering SWCC model selection and parameter uncertainties," Engineering Geology, vol. 260, article 105207, 2019.

[25] S.-H. Jiang, J. Huang, X.-H. Qi, and C.-B. Zhou, "Efficient probabilistic back analysis of spatially varying soil parameters for slope reliability assessment," Engineering Geology, vol. 271, p. 105597, 2020.

[26] H. Haario, M. Laine, A. Mira, and E. Saksman, "DRAM: efficient adaptive MCMC," Statistics and Computing, vol. 16, no. 4, pp. 339-354, 2006.

[27] E. Gaume, L. Gaál, A. Viglione, J. Szolgay, S. Kohnová, and G. Blöschl, "Bayesian MCMC approach to regional flood frequency analyses involving extraordinary flood events at ungauged sites," Journal of Hydrology, vol. 394, no. 1-2, pp. 101-117, 2010.

[28] Y. Wang, S.-K. Au, and Z. Cao, "Bayesian approach for probabilistic characterization of sand friction angles," Engineering Geology, vol. 114, no. 3-4, pp. 354-363, 2010.

[29] J. Huang, R. Kelly, D. Li, C. Zhou, and S. Sloan, "Updating reliability of single piles and pile groups by load tests," Computers and Geotechnics, vol. 73, pp. 221-230, 2016.

[30] C. Chiu, W. Yan, and K.-V. Yuen, "Reliability analysis of soilwater characteristics curve and its application to slope stability analysis," Engineering Geology, vol. 135, pp. 83-91, 2012.

[31] W. Liu, X. Luo, F. Huang, and M. Fu, "Uncertainty of the soilwater characteristic curve and its effects on slope seepage and stability analysis under conditions of rainfall using the Markov chain Monte Carlo method," Water, vol. 9, no. 10, 2017.

[32] H. Chen, C. Lee, and K. Law, "Causative mechanisms of rainfall-induced fill slope failures," Journal of Geotechnical and Geoenvironmental Engineering, vol. 130, no. 6, pp. 593$602,2004$.

[33] L. Zhang, L. Zhang, and W. Tang, "Rainfall-induced slope failure considering variability of soil properties," Géotechniqu, vol. 55, no. 2, pp. 183-188, 2004.

[34] H. Rahardjo, T. Ong, R. Rezaur, and E. C. Leong, "Factors controlling instability of homogeneous soil slopes under rainfall," Journal of Geotechnical and Geoenvironmental Engineering, vol. 133, no. 12, pp. 1532-1543, 2007.

[35] M. Bordoni, C. Meisina, R. Valentino, N. Lu, M. Bittelli, and S. Chersich, "Hydrological factors affecting rainfall-induced shallow landslides: from the field monitoring to a simplified slope stability analysis," Engineering Geology, vol. 193, pp. 19-37, 2015.

[36] C. Cao, Q. Wang, J. Chen et al., "Landslide susceptibility mapping in vertical distribution law of precipitation area: case of the Xulong hydropower station reservoir, Southwestern China," Water, vol. 8, no. 7, p. 270, 2016.

[37] F. Huang, X. Luo, and W. Liu, "Stability analysis of hydrodynamic pressure landslides with different permeability coefficients affected by reservoir water level fluctuations and rainstorms," Water, vol. 9, no. 7, p. 450, 2017.

[38] R. L. Michalowski, "Stability charts for uniform slopes," Journal of Geotechnical and Geoenvironmental Engineering, vol. 128, no. 4, pp. 351-355, 2002.

[39] J. M. Duncan and S. G. Wright, Soil Strength and Slope Stability, John Wiley \& Sons, Inc. (WILEY), 2005.

[40] N. Lu, B. Şener-Kaya, A. Wayllace, and J. W. Godt, “Analysis of rainfall-induced slope instability using a field of local factor of safety," Water Resources Research, vol. 48, no. 9, 2012.

[41] C. Kristo, H. Rahardjo, and A. Satyanaga, "Effect of hysteresis on the stability of residual soil slope," International Soil and Water Conservation Research, vol. 7, no. 3, pp. 226-238, 2019.

[42] W. Gardner, "Some steady-state solutions of the unsaturated moisture flow equation with application to evaporation from a water table," Soil Science, vol. 85, no. 4, pp. 228-232, 1958.

[43] M. T. van Genuchten, "A closed-form equation for predicting the hydraulic conductivity of unsaturated soils," Soil Science Society of America Journal, vol. 44, no. 5, pp. 892-898, 1980.

[44] P. Milly, "Estimation of Brooks-Corey parameters from water retention data," Water Resources Research, vol. 23, no. 6, pp. 1085-1089, 1987.

[45] D. Fredlund, A. Xing, and S. Huang, "Predicting the permeability function for unsaturated soils using the soil-water characteristic curve," Canadian Geotechnical Journal, vol. 31, no. 4, pp. 533-546, 1994.

[46] S. H. Krishnapillai and N. Ravichandran, "New soil-water characteristic curve and its performance in the finite-element simulation of unsaturated soils," International Journal of Geomechanics, vol. 12, no. 3, pp. 209-219, 2012.

[47] K.-K. Phoon, A. Santoso, and Y. Cheng, "Probabilistic analysis of soil water characteristic curves from sandy clay loam," in GeoCongress 2008: Characterization, Monitoring, and Modeling of GeoSystems, pp. 917-925, New Orleans, Louisiana, 2008.

[48] G. B. Baecher and J. T. Christian, Reliability and Statistics in Geotechnical Engineering, John Wiley \& Sons, 2005.

[49] J. Gill, Bayesian Methods: A Social and Behavioral Sciences Approach, vol. 20, CRC press, 2014.

[50] C. Feng, B. Tian, X. Lu et al., "Bayesian updating of soil-water character curve parameters based on the monitor data of a large-scale landslide model experiment," Applied Sciences, vol. 10, no. 16, article 5526, 2020.

[51] N. Metropolis, A. W. Rosenbluth, M. N. Rosenbluth, A. H. Teller, and E. Teller, "Equation of state calculations by fast computing machines," The Journal of Chemical Physics, vol. 21, no. 6, pp. 1087-1092, 1953.

[52] W. K. Hastings, "Monte Carlo sampling methods using Markov chains and their applications," Biometrika, vol. 57, no. 1, pp. 97-109, 1970.

[53] C. Hsein Juang, Z. Luo, S. Atamturktur, and H. Huang, "Bayesian updating of soil parameters for braced excavations using field observations," Journal of Geotechnical and Geoenvironmental Engineering, vol. 139, no. 3, pp. 395-406, 2012. 
[54] L. Zhang, Z. Zuo, G. Ye, D. Jeng, and J. Wang, "Probabilistic parameter estimation and predictive uncertainty based on field measurements for unsaturated soil slope," Computers and Geotechnics, vol. 48, pp. 72-81, 2013.

[55] J. A. Vrugt, C. J. Ter Braak, M. P. Clark, J. M. Hyman, and B. A. Robinson, "Treatment of input uncertainty in hydrologic modeling: doing hydrology backward with Markov chain Monte Carlo simulation," Water Resources Research, vol. 44, no. 12, 2008.

[56] L. Tierney and A. Mira, "Some adaptive Monte Carlo methods for Bayesian inference," Statistics in Medicine, vol. 18, no. 1718, pp. 2507-2515, 1999.

[57] H. Haario, E. Saksman, and J. Tamminen, "An adaptive Metropolis algorithm,” Bernoulli, vol. 7, no. 2, pp. 223-242, 2001.

[58] A. Mira, "On Metropolis-Hastings algorithms with delayed rejection," Metron, vol. 59, no. 3-4, pp. 231-241, 2001.

[59] J. Šimůnek, M. T. van Genuchten, and M. Šejna, “Development and applications of the HYDRUS and STANMOD software packages and related codes," Vadose Zone Journal, vol. 7, no. 2, pp. 587-600, 2008.

[60] E. Conte and A. Troncone, "A method for the analysis of soil slips triggered by rainfall," Geotechnique, vol. 62, no. 3, p. 187, 2012.

[61] L. Zhang, Y. Zheng, L. Zhang, X. Li, and J. Wang, "Probabilistic model calibration for soil slope under rainfall: effects of measurement duration and frequency in field monitoring," Géotechnique, vol. 64, no. 5, p. 365, 2014.

[62] E. Conte, A. Donato, and A. Troncone, "A simplified method for predicting rainfall-induced mobility of active landslides," Landslides, vol. 14, no. 1, pp. 35-45, 2017. 